\title{
Japanese experience in stakeholder involvement: ICRP Dialogue meetings
}

\author{
N. Ban \\ Nuclear Regulation Authority, 1-9-9 Roppongi, Minato-ku, Tokyo 106-8450, Japan.
}

\begin{abstract}
The International Commission on Radiological Protection initiated a forum for dialogue with the parties concerned (ICRP Dialogue) to support the rehabilitation of living conditions after the Fukushima nuclear accident. Ten meetings have been held as of the end of 2014, involving a wide variety of participants including the local residents, authorities, NPOs, experts, professionals, media and foreign representatives. Through sharing information and experiences among various parties, the Dialogues have fostered an awareness of the human dimension and the importance of self-help protective actions assisted by relevant experts. Such understanding will be essential for the development and implementation of a radiological protection strategy in the complex situations of the affected areas.
\end{abstract}

Keywords: Fukushima accident / ICRP Dialogue seminars / rehabilitation of living conditions / stakeholder involvement

\section{Introduction}

Since the accident at Fukushima Dai-ichi nuclear power station, efforts have been made to mitigate doses to the public in the contaminated areas. However, as demonstrated in the Chernobyl accident, existing exposure situations resulting from a nuclear accident cannot be managed with radiation protection considerations alone (Lochard, 2007). Various aspects of people's daily living are affected, and a wide range of nonradiological issues also need to be addressed. In its recommendations for the protection of people living in long-term contaminated areas, the International Commission on Radiological Protection (ICRP) emphasizes the importance of involving representatives of the affected population and relevant experts in the management of such complex situations (ICRP, 2009). In this perspective, ICRP together with the Radiation Safety Forum Japan took the initiative to organize a forum for Dialogue with the parties concerned. The present paper provides an overview of this forum, ICRP Dialogues "Rehabilitation of Living Conditions after the Fukushima Accident".

\section{Issues discussed}

The first Dialogue was held in fall 2011 in Fukushima City. Since then a total of 10 Dialogue meetings have been held as of the end of 2014 as shown in Table 1.

The first two Dialogue meetings concentrated on understanding the situation and identifying problems in the affected areas. From the third Dialogue, discussions were focused on more specific issues. After a series of meetings took place in Date City, the Dialogue extended to other districts to face particular problems in each community. The 6th Dialogue was dedicated to the people of Iitate Village, who had evacuated and are still living in exile. The 7th Dialogue demonstrated the effectiveness of self-help protective actions in some communities. The 8th Dialogue highlighted a complex situation in a coastal area which is suffering from fragmentation of the community. The last two Dialogue meetings came back to specific topics with greater emphasis on the human dimension. A summary of each Dialogue is available from the ICRP website ${ }^{1}$.

\section{Parties involved}

ICRP Dialogues are intended to provide an opportunity to share experience and promote radiological protection culture in the affected areas. A wide variety of people have been involved in this context. The main emphasis is on local communities, and parties who are interested in the specific aspect of their living conditions participate in the meetings. For example, when the management of food contamination was a topic, local farmers, distributors and consumers, including those from outside the regions, got together to discuss what was of concern from each standpoint. Experts and professionals of the relevant field provide scientific information and practical experience. Authorities and Non-Profit Organizations (NPOs) explain ongoing efforts to support the affected population, and the media assess the situation from a

\footnotetext{
1 http://www.icrp.org/page.asp?id=189
} 
Table 1. Chronicle of ICRP Dialogue meetings in Fukushima.

\begin{tabular}{lccc}
\hline & Date & Place & Main Subject \\
\hline 1. & 26-27 November 2011 & Fukushima City & Problems in general \\
\hline. & 25-26 February 2012 & Date City & Problems in Date \\
\hline 3. & 7-8 July 2012 & Date City & Food production and distribution \\
\hline. & 10-11 November 2012 & Date City & Education at school \\
\hline 5. & 2-3 March 2013 & Date City & Returning (staying) or not \\
6. & 6-7 July 2013 & Fukushima City & Problems for Iitate people \\
7. & 30 November-1 December 2013 & Iwaki City & Challenges in Iwaki \\
8. & 10-11 May 2014 & Minami-soma City & Problems in Minamisoma \\
9. & 30-31 August 2014 & Date City & Raising children \\
10. & 6-7 December 2014 & Date City & Value of tradition and culture \\
\hline
\end{tabular}
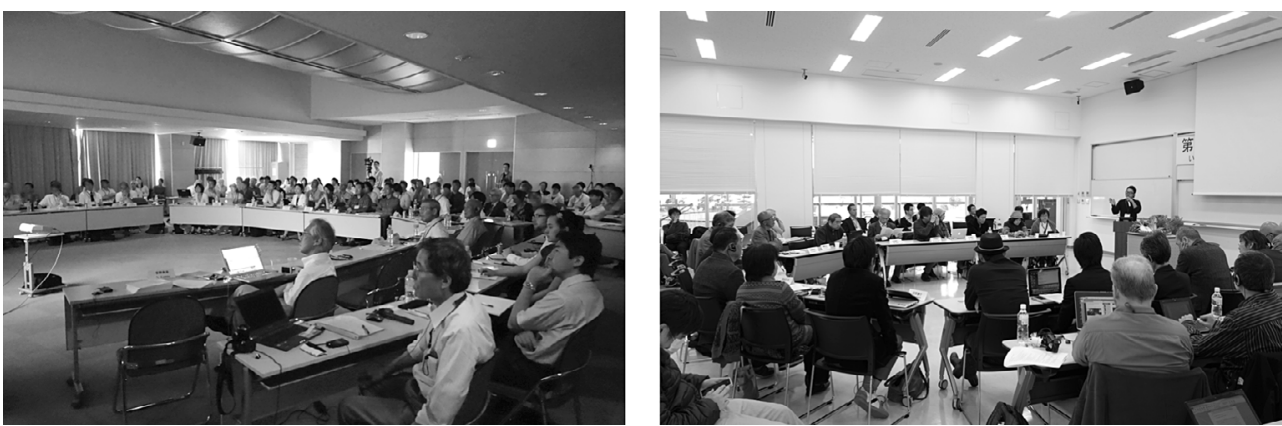

Figure 1. Meeting scenes from the 6th (left) and the 7th (right) Dialogues (Photo by Kazuya Kanazawa).

bigger perspective. Representatives of Belarusian, Norwegian and French organizations play a crucial part with direct experience in managing long-term consequences of the Chernobyl accident. Inhabitants of the areas contaminated by the Chernobyl accident are sometimes invited to share their experience. Representatives of the Committee on Radiation Protection and Public Health (CRPPH) of the OECD Nuclear Energy Agency and some ICRP members also participate in the meetings. While there are some regular attendants, the most relevant parties are invited depending on the subject for discussion.

\section{Form of the meeting}

Every Dialogue meeting is held over a weekend as a two-day program. Jacques Lochard, vice-chair of the ICRP, presides over the meeting. To share his talk as a moderator and presentations by foreign representatives, simultaneous translation between English and Japanese is provided.

Table 2 shows a typical program of the Dialogue. In the opening, participants are requested to introduce themselves with their name, profession and experience. The presentation session includes reports from the local residents, NPOs experts, professionals and foreign representatives. In the dialogue session, the moderator asks "what is at stake" for the topic, and designated speakers one by one express their views on the question. After finishing the first round, they are asked to express their views again in reaction to what has been said by the others. Throughout the session, any remark is respected, and no question or interruption is allowed. A foreign representative is appointed as a rapporteur to present a summary of the
Table 2. Typical program of a Dialogue meeting.

\begin{tabular}{ll}
\hline & - Opening \\
Day 1 & - Presentation session \\
& - Dialogue session \\
& - Rapporteur's report and discussion \\
& - Reception \\
\hline & - Presentation session \\
& - Dialogue session \\
Day 2 & - Rapporteur's report and discussion \\
& - Summary \\
& - Concluding remark \\
\hline
\end{tabular}

dialogue session. It is followed by a free-form discussion in which participants other than the speakers also get involved. The form of the meeting is basically the same on the second day, but the questions asked in the dialogue session are more forward-looking, such as "how to move forward".

Figure 1 illustrates the setting of the Dialogue meetings. Designated speakers sit in round-table format, and behind them are the other participants who do not speak in the dialogue session (observers). As shown in these pictures, the Dialogues are convened in a consistent way even though the location of the meeting is changed.

\section{Benefits of the dialogue}

The Dialogue helped share experience and facilitated mutual understanding between diverse parties. It has demonstrated that situations vary among communities and perception of the situation is different from person to person. It has also 
been confirmed that self-help protective actions can be a key for the people to regain control of their lives, and expertise and support from the relevant experts are essential. In this context, experts should pursue "co-expertise" which not only explains the situation but also suggests some actions to resolve the problems together with the people. The Dialogues gave testimony to this approach, and at the same time, served as a catalyst to connect local residents with experts/professionals who were willing to assist them.

\section{Conclusion}

The ICRP Dialogues are an attempt to initiate stakeholder involvement in the existing exposure situations after the Fukushima nuclear accident. Through sharing information and experiences among various parties, the Dialogues have fostered an awareness of the human dimension and the importance of co-expertise to support self-help protective actions. Such understanding will be essential for the development and implementation of a radiological protection strategy in the affected areas under complex situations.

\section{References}

ICRP Publication 111 (2009) Application of the Commission's Recommendations to the Protection of People Living in Longterm Contaminated Areas after a Nuclear Accident or a Radiation Emergency, Ann. ICRP 39 (3).

Lochard J. (2007) Rehabilitation of Living Conditions in Territories Contaminated by the Chernobyl Accident: The Ethos Project, Health Phys. 93 (5), 522-526.

Cite this article as: N. Ban. Japanese experience in stakeholder involvement: ICRP Dialogue meetings. Radioprotection 51(HS1), S51-S53 (2016). 